\title{
A distribuição geográfica das estações locais de TV no Brasil
}

\section{The geographical distribution of local TV stations in Brazil}

\author{
Octavio Penna Pieranti \\ Núcleo de Estudos de Administração Brasileira (Abras-UFF) e Laboratório de Estudos em Comunicação, Tecnologia e Educação \\ Cidadã da Universidade Estadual Paulista Júlio de Mesquita Filho (Lecotec-Unesp). \\ ORCID: 0000-0002-2719-2431 \\ <octavio.pieranti@gmail.com>
}

\section{Como citar este artigo (How to cite this article): \\ PIERANTI, Octavio Penna. A distribuição geográfica das estações locais de TV no Brasil. Revista Famecos, Porto Alegre, v. 25, n. 3, p. 1-19, setembro, outubro, novembro e dezembro de 2018: ID30181. DOI: http://dx.doi.org/10.15448/1980-3729.2018.3.30181.}

\section{RESUMO}

ATV expandiu-se, no Brasil, de forma pouco planejada, configurando um cenário de desigualdades regionais. Este artigo analisa a distribuição geográfica das estações locais de TV e questiona se ela, no Brasil, pode ser efetivamente caracterizada como meio de comunicação local. Para atingir esse objetivo, o autor promoveu o cruzamento de bases de dados públicas, do IBGE e da Anatel, em perspectiva não adotada em estudos anteriores. Verificou-se, por fim, que apenas pouco mais da metade dos cidadãos residentes no país tem acesso a pelo menos um canal que insira programação localmente. A maior parte desses canais legalmente pode inserir conteúdos por pouco tempo. Observa-se, também, desigualdade regional na distribuição dessas outorgas, em parte graças à política de incentivo específica voltada à região da Amazônia Legal.

\begin{abstract}
TV has expanded in Brazil in an unplanned manner, creating a scenario of regional inequalities. This article analyzes the geographical distribution of local TV stations, and questions whether the medium can be effectively characterized as local in Brazil. In order to reach this objective, the author used public databases, published by IBGE and Anatel, a perspective which has not yet been adopted by previous studies. Lastly, it was found that only nearly half of the citizens have access to at least one channel that transmits local content. Most of these channels can only broadcast local content for short periods, due to legal restrictions. Regional inequality in the distribution of licenses was also identified, an aspect that can be partly explained by specific incentive policies focused on the "Legal Amazon" region.
\end{abstract}

Keywords: TV. Retransmitters. “Legal Amazon”.

\section{Introdução}

A TV expandiu-se, no Brasil, a partir dos grandes centros. As estações esparsas e sem integração foram, na década de 1960, submetidas a uma outra lógica de operação e dinâmica de produção. Com os investimentos - em grande parte, públicos - na infraestrutura de telecomunicações, as antigas estações passaram a operar em rede, progressivamente ganhando capilaridade rumo ao interior do país. 
Essa história é conhecida e declamada há algumas décadas. Interessa a este artigo, neste momento, dois aspectos a ela relacionados. $O$ primeiro: a expansão seguiu uma lógica eminentemente econômica, contemplando, de forma mais acelerada, municípios onde havia uma probabilidade de obtenção de receitas mais rapidamente. São os municípios economicamente "interessantes", sob a ótica do mercado. Como a opção nacional - se não teórica, fática - foi por estimular a formação de grandes redes comerciais em um contexto pouco regulado, o resultado não podia ser diferente.

À poucaregulaçãosomou-seainexistência depolíticas públicasduradouras que enfocassem o planejamento dessa expansão - e é esse o segundo ponto que se quer destacar. Em poucos momentos, o Estado preocupou-se em definir, com base em critérios socioeconômicos e de forma transparente, quais deveriam ser os próximos municípios a serem contemplados com novas emissoras. Ainda que tenha havido, historicamente, uma preocupação com a gestão técnica do espectro de frequências, as outorgas foram totalmente discricionárias, a critério do governo do momento, até a segunda metade da década de 1990, quando começaram a ter que obedecer a processos seletivos. Mesmo assim, esse esforço de regulamentação estendeu-se até meados da atual década, destacando-se o período entre 2011 e 2016, quando ritos de concorrência por novas outorgas de alguns serviços de radiodifusão foram estabelecidos pela primeira vez (caso de radiodifusão educativa e retransmissoras de TV primárias) e outros foram aprimorados (radiodifusão comercial e comunitária).

De forma mais estruturada, ainda houve, nessa mesma fase, uma tentativa de planejar outorgas futuras, por meio dos Planos Nacionais de Outorgas (PNO). Em 2011, porém, a fase de implantação da radiodifusão no Brasil já estava, em grande parte, concluída. Além disso, o governo iniciado em 2016 interrompeu se não oficialmente, na prática, pelo menos até o momento em que escrevo - a publicação de novos processos seletivos, anteriormente divulgados. Com isso, abreviou, também, a própria política consubstanciada nos Planos Nacionais de Outorgas (PNO).

Outra forma de atuação do Estado nesse setor foi a operação direta de estações. $O$ exemplo mais visível são as redes que construiu, a partir de marcas importantes e emissoras simbólicas, ainda que com resultados ruins em termos de audiência. Grande parte dessas emissoras é hoje operada pela Empresa Brasil de Comunicação (EBC). Mas o lado menos visível dessa atuação é o que mais dialoga com os objetivos deste trabalho: prefeituras de pequenos e médios municípios, onde supostamente não havia interesse comercial, contribuíram, de forma significativa, para a expansão da radiodifusão. Com recursos públicos, foram instaladas, ao longo do tempo, milhares de retransmissoras de TV pelo 
país - para retransmitir sinais de redes privadas, eventualmente com inserção de conteúdos locais.

O objetivo deste artigo é analisar o que resultou desse cenário de omissões, planejamentos incompletos, políticas públicas implementadas parcialmente e regulamentação tardia. Mais especificamente, apresenta-se e avalia-se, aqui, o cenário da distribuição geográfica das estações locais de TV no Brasil e questiona-se se, de fato, a TV, no contexto nacional, pode ser encarada como meio apto a oferecer informações e debater realidades locais.

Este artigo preocupa-se em traduzir, em números e a partir de bases de dados públicas, o cenário das outorgas de TV no país e suas desigualdades regionais, até certo ponto, surpreendentes. Acredita-se que esta seja a principal contribuição do artigo para estudos futuros sobre o cenário da radiodifusão no país, bem como sobre a avaliação de políticas públicas (ou sobre sua ausência).

\section{Considerações metodológicas}

Como apresentado na seção anterior, este artigo tem, como unidade básica de análise, "estações locais de TV". Assim, faz-se necessário, de início, definir o conceito, desdobrando-o em duas partes.

A primeira diz respeito à expressão "local". Aqui, o termo será usado como sinônimo de "município". Do ponto de vista legal, conforme previsto nos art. $1^{\circ}$ e 18 da Constituição Federal, esta é a menor unidade político-administrativa da República. No caso específico da TV, as outorgas são expedidas para um município específico (e apenas eventualmente para um distrito), ainda que seu sinal extrapole as divisas municipais. Assim, para efeitos deste artigo, as "estações locais de TV" são as estações localizadas em um dado município.

Por ora, o conceito ainda não é claro. Faz-se necessário, portanto, definir "estação de TV". Usualmente essa expressão é utilizada, em textos não técnicos, como sinônimo degeradora de radiodifusão de sons eimagens, ou seja, emissoras de TV. Refere-se, portanto, à chamada "TV aberta", o que forçosamente exclui a TV por Assinatura ou serviços e plataformas que façam uso de outra rede - por exemplo, a internet -, ainda que possam ser assistidas em um aparelho de TV. A geradora de TV guarda, ainda, um elemento que a diferencia de retransmissoras (RTVs) e de repetidoras (RpTVs): ela pode transmitir programação inserida localmente (ou seja, no próprio município, nos termos da definição proposta). Como se verá adiante, há um outro tipo de outorga que também pode transmitir programação inserida localmente - as RTVs estabelecidas na Amazônia Legal. Assim, o conceito de "estações locais de TV" está sendo definido como aquelas estações que podem transmitir programação inserida localmente (no próprio município), faculdade relacionada à natureza da outorga (caso das geradoras) 
ou a condições especiais relacionadas à localidade em que operam (caso das RTVs da Amazônia Legal).

A pesquisa fezuso de duas bases públicas de dados distintas, ambasobtidas no dia seis de novembro de 2017. A primeira é a dos municípios brasileiros e suas respectivas populações, conforme disponibilizado pelo Instituto Brasileiro de Geografia e Estatística (IBGE, 2017). A segunda é disponibilizada publicamente pela Agência Nacional de Telecomunicações, mais especificamente pelo Sistema Mosaico (Anatel, 2017), e reúne todas as outorgas de geradoras de TV e de retransmissoras de TV (além de emissoras comerciais e educativas em FM e AM) do Brasil. O cruzamento das duas bases de dados, conforme se verá adiante, permitiu a abordagem original que se tentou conferir a este artigo, qual seja, o exame da capilaridade do meio TV e, mais especificamente, da comunicação local, nos diferentes contextos regionais do país.

No Sistema Mosaico, cada ato de pós-outorga implica em uma nova entrada na base de dados. Por exemplo: se é feita uma alteração de características técnicas em uma emissora, a planilha passa a incluir uma nova linha a ela referente - ou seja, cada outorga é representada por várias linhas de uma mesma planilha. Assim, uma etapa inicial envolveu o tratamento desta base: primeiro foram filtrados os serviços de radiodifusão buscados (TV e RTV), reduzindo-se a base de 97.159 para 40.607 entradas; e, a seguir, foram excluídas entradas que se referiam a uma mesma outorga, logo cada estação passou a aparecer uma única vez.

Além disso, no processo de migração para a TV Digital, a cada estação analógica está sendo atribuída uma nova consignação, o chamado "par digital". Dessa forma, cada estação também aparece duplicada na base, com uma entrada para o cenário analógico e outra, para o digital. Optou-se por trabalhar com a base de estações analógicas, já que ainda não é significativo o número de novas outorgas que operam apenas no contexto digital.

Ressalte-se que esta análise só foi possível graças à disponibilização pública dessas bases de dados, o que está relacionado a avanços observados, ao longo dos últimos dez anos, no que tange à transparência de dados públicos. A síntese desses avanços é a lei no 12.527 de 2011, conhecida como Lei de Acesso à Informação. No entanto, a defesa da transparência não pode se restringir à sua afirmação no marco legal; ela deve ser construída, trabalhada e reforçada pela sociedade, sendo os pesquisadores elementos-chave nesse processo. 


\section{Nota sobre a morte não morrida da TV}

A expansão do acesso à internet tem provocado, há vários anos, debates inconclusivos sobre o futuro daTV. Estaria esse meio fadado ao desaparecimento? Ou, talvez, à irrelevância? Quem sabe ele poderia se adequar aos novos tempos, revolvendo sua própria natureza, inspirando-se nas redes sociais, buscando uma assincronia na programação e amoldando-se a interesses de cada telespectador? (Loureiro, 2009, p. 464; Coutinho; Mata, 2010)

Em 2018, uma pesquisa que trata da expansão do meio TV e de sua centralidade no dia-a-dia da sociedade não pode ignorar essas perguntas, sob o risco de ser acusado de descolamento da realidade. Este artigo as reconhece como pano de fundo, mas não aprofundará este debate. Na verdade, adota outro ponto de partida: prognósticos sinistros à parte, entende que a TV não só é importante, como ganha relevância. Mais que isso: mesmo que tenha feito concessões aqui e ali, em termos de conteúdos, aos novos tempos - com testes de novos formatos e abordagem de temas e perspectivas incomuns até então - , a "velha"TV continua desempenhando papel essencial, que possivelmente se estenderá, ainda, por décadas no Brasil. Por "velha" TV, refiro-me à radiodifusão tradicional, à TV "aberta", com programação linear e já consagrada, disputando audiência da forma reconhecida e habitual.

É preciso explicar essa perspectiva. Notícias recentes reforçam que a TV apresenta, nos últimos anos, resultados positivos, o que pode ser considerado surpreendente. De janeiro a agosto de 2017, a média de televisores ligados no país foi de inéditos $47 \%$, o que representava um crescimento de $17,5 \%$ em relação ao mesmo período cinco anos antes. Globo e Record, também nos oito primeiros meses de 2017, superaram seus melhores índices médios de audiência, registrados cinco e seis anos antes respectivamente. Mais da metade dos brasileiros mencionava, na mesma época, que a TV é sua fonte principal na busca por notícias. Observava-se, então, que a "TV aberta" era a responsável, inclusive, por inspirar conteúdos de sucesso em outras plataformas mais recentes (Castro, 2017; Feltrin, 2017; Poder360, 2017).

Esses números são similares aos observados na Pesquisa Brasileira de Mídia, realizada pela Secretaria de Comunicação Social da Presidência da República (Secom-PR) de 2014 a 2016. Em 2016, os entrevistados tiveram que responder sobre os meios de comunicação que mais acessavam para buscar informações sobre o Brasil. Os resultados podem ser observados nos gráficos abaixo: 
- Gráfico 1: Meios mais usados para buscar informações sobre o Brasil (\%)

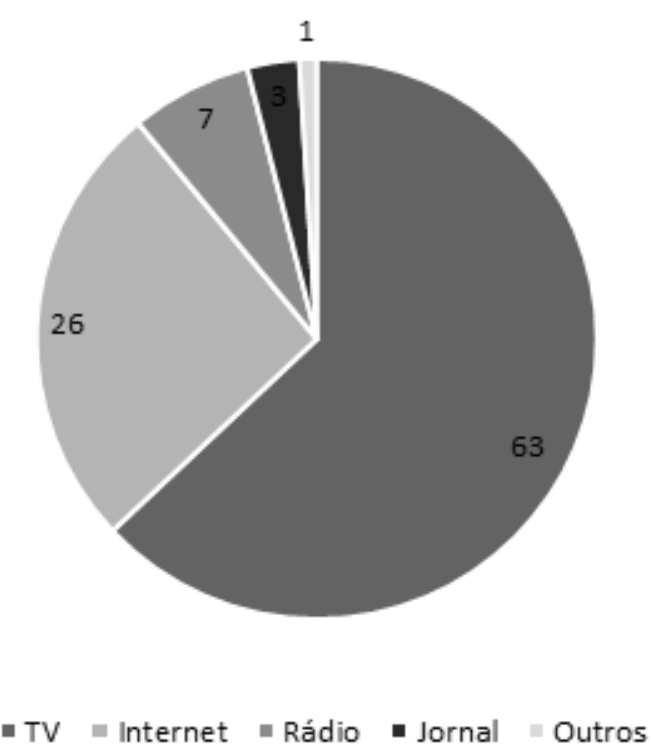

Fonte: Elaborado pelo autor, com base em Secom (2016)

Gráfico 2: Meios mais usados para buscar informações sobre o Brasil ( $1^{\text {a }}$ e $2^{\mathrm{a}}$ menções - em \%)

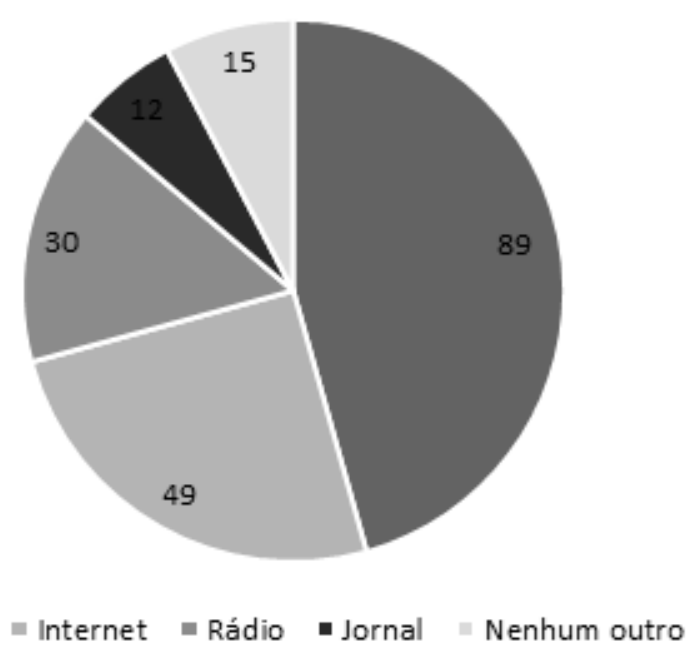

Fonte: Elaborado pelo autor, com base em Secom (2016)

Observa-se que a TV foi o meio mais citado em 63\% dos casos. Quando os entrevistados podiam citar dois meios, a TV foi mencionada em $89 \%$ das respostas. Se observada a série histórica da pesquisa, é possível verificar que, entre 2014 e 2016, aumentou o percentual de brasileiros que dizia usar a TV em seis ou sete dias da semana, ao passo que permanecia estável o percentual de entrevistados que dizia nunca usar esse meio: 
Tabela 1: Uso semanal do meio TV (\%)

\begin{tabular}{|l|l|l|l|}
\hline TV & PBM 2014 & PBM 2015 & PBM 2016 \\
\hline 7x por semana & 65 & 73 & 77 \\
\hline 6x por semana & 3 & 4 & 2 \\
\hline NUNCA & 3 & 4 & 3 \\
\hline
\end{tabular}

Fonte: Pieranti (2017)

O desempenho positivo do meio TV não é observado, nos últimos anos, apenas no Brasil. Em 2016, os telespectadores europeus assistiram, em média, 3h40m de TV por dia, número superior, em quatro minutos, ao verificado em 2011. Em 2015, os países líderes nesta medição eram a Bósnia (onde cada cidadão assistia TV, em média, por 5h40m diárias), Romênia (5h29m) e Sérvia (5h15m), ao passo que Islândia ( $1 \mathrm{~h} 50 \mathrm{~m})$ e Suíça $(2 \mathrm{~h} 04 \mathrm{~m}$, nos cantões germânicos) eram as nações onde menos se assistia. (EBU, 2016; EBU, 2017).

Não se pretende, aqui, definir uma razão para os resultados expressivos da TV no Brasil e na Europa. Especulações são possíveis: a TV continua ligada, mas progressivamente o cidadão a adota como segunda tela, enquanto navega pela internet; ou a crise econômica vivida por diversos países, nos últimos anos, força a permanência em casa e a busca por diversão gratuita. Nenhuma dessas ou de outras possíveis razões, contudo, diminui a relevância da TV como meio de informação para as sociedades contemporâneas. Ainda mais digno de nota: como a interatividade em massa e possibilidades de exibição de programação não linear na radiodifusão ainda estão distantes da realidade, resta concluir que é a "velha" TV a responsável por alcançar resultados positivos. E é desta "velha" $\mathrm{TV}$, atraente e, por isso mesmo, relevante, que trata este artigo.

\section{As retransmissoras na expansão dos sinais de TV}

Como mencionado anteriormente, a legislação brasileira prevê dois tipos de outorgas que configuram as "estações locais de TV". A primeira reúne as 538 geradoras que podem inserir programação própria localmente e estão registradas na base de dados da Anatel, no Sistema Mosaico. A segunda envolve as 11.493 RTVs, das quais 1.696 (14,75\%) podem inserir programação, já que localizadas na Amazônia Legal.

O decreto ${ }^{\circ}$ 5.371, de 17 de fevereiro de 2005, aprova o atual Regulamento do Serviço de Retransmissão de Televisão e do Serviço de Repetição de Televisão. Tal como as normas que o antecederam, esse decreto volta a afirmar que as retransmissoras têm, como função precípua, a veiculação de 
programação idêntica à das geradoras, permitindo que seus sinais cheguem a municípios diretamente não cobertos por elas. Assim, as atuais retransmissoras garantem, na prática, a formação das redes nacionais e regionais. Para atingir esse objetivo, aplicam-se a elas algumas condições especiais: são objeto de outorgas simplificadas (ou seja, processos mais simples e céleres, sem necessidade de aprovação pelo Congresso Nacional, por exemplo); em grande parte discricionárias, a critério do titular do Ministério da Ciência, Tecnologia, Inovações e Comunicações (MCTIC); e gratuitas.

Também como normas anteriores que remetem ao fim da década de 1970, o decreto, em seu art. 33, volta a afirmar que uma RTV poderá veicular até $15 \%$ de programação ( $3 \mathrm{~h} 36 \mathrm{~m}$, considerando um total de $24 \mathrm{~h}$ ), incluindo publicidade, inserida localmente "em regiões de fronteira de desenvolvimento do País, assim definidas em ato do Ministro de Estado das Comunicações" (antecessor do MCTIC).

Desde 1989, por meio da Portaria no 93, de 19 de julho daquele ano, o Ministério das Comunicações reconheceu que essas "regiões de fronteiras de desenvolvimento" são as integrantes da Amazônia Legal, definida pela Lei no 5.173, de 27 de outubro de 1966. A elas viria a se somar o Arquipélago de Fernando de Noronha.

Antes da definição propriamente dita da Amazônia Legal, cabe ressaltar a razão de ser da criação dessa região diferenciada. Em 1966, tendo em vista a preocupação do Estado com o baixo desenvolvimento econômico da área, sua população rarefeita e riquezas naturais abundantes, a nova lei previu o Plano de Valorização Econômica da Amazônia e criou a Superintendência do Desenvolvimento da Amazônia (SUDAM), sucedânea da Superintendência do Plano de Valorização Econômica da Amazônia (SPVEA). Ao novo órgão caberia a elaboração do plano propriamente dito e a implementação de uma série de medidas especiais voltadas ao fomento de atividades econômicas na região. Um dos resultados mais explícitos desse conjunto de medidas foi a criação da Zona Franca de Manaus.

Inicialmente a Amazônia - depois chamada de "Amazônia Legal" compreenderia os estados do Acre, Pará e Amazonas; os territórios federais do Amapá, Roraima e Rondônia (depois transformados em estados); parte do Mato Grosso (o norte do estado, que viria a ser o estado do Mato Grosso, quando da criação do Mato Grosso do Sul) e de Goiás (nesse caso, área que viria a constituir o Tocantins); e parte do Maranhão, a oeste do meridiano de 44․ Seriam, portanto, nove estados, incluindo toda a região Norte; o estado do Mato Grosso (abarcando, por fim, todos os seus municípios); e a maior parte dos municípios maranhenses, na prática o único estado que não figura, por inteiro, 
nessa área especial de desenvolvimento. Atualmente, o total de 772 municípios da Amazônia Legal equivale a $13,86 \%$ de todos os existentes no país. Aí residem, ainda, $13,04 \%$ da população de todo o país.

Ao conjunto de medidas econômicas voltadas ao desenvolvimento da Amazônia Legal, o governo federal somou uma especificamente no âmbito das comunicações: a permissão para que as RTVs, nessa região, veiculem parte da programação produzida localmente. Essa permissão, em tese, gera efeitos para além do setor de radiodifusão, já que também pode estimular o estabelecimento de produtoras de conteúdo audiovisual, além de criar empregos para jornalistas, radialistas e profissionais atuantes no campo da comunicação.

Lobato pesquisou recentemente a situação das RTVs da Amazônia Legal. Em 2015 e 2016, realizou três expedições para a região, para mais de 30 municípios de quatro estados, além de mais de 200 entrevistas. Dividiu os donos das estações entre empresários (ainda a maioria); políticos; e igrejas (o grupo que mais cresce). Retratou como as retransmissoras funcionam, na prática, como "miniemissoras", em que normalmente telejornais predominam na cota de conteúdo produzido e inserido no plano local. E, quando esse conteúdo vai ao ar, as emissoras e retransmissoras que estão veiculando conteúdo nacional são frequentemente derrotadas na guerra por audiência (Lobato, 2017, p. 44).

Nahistória da radiodifusãono país, RTVsjá estiveram, emalgunsmomentos, no centro de polêmicas. Como exemplo, pode ser citada a pesquisa de Costa e Brener (1997), que apontaram um processo acelerado de novas outorgas às vésperas da votação de projeto de emenda constitucional que viria a garantir a possibilidade de reeleição do Presidente da República, Fernando Henrique Cardoso (o que se concretizaria na eleição subsequente). Na prática, de acordo com os autores, isso significou o surgimento de 1848 novas RTVs, das quais 527 autorizadas a empresas de comunicação; 479 a prefeituras; 472 a empresas e entidades ligadas a igrejas; 102 a fundações educativas; e 268 a empresas ou entidades controladas por 87 políticos. Desse último grupo, ainda conforme os autores, dezenove deputados e seis senadores votaram favoravelmente à emenda constitucional em discussão. A lista de beneficiados incluía, ainda, dois governadores, onze deputados estaduais, sete prefeitos, oito ex-deputados federais, três ex-governadores, oito ex-prefeitos e outros 23 políticos. 0 ritmo de outorgas foi intensificado um mês antes da votação em primeiro turno da emenda na Câmara dos Deputados, quando foram autorizadas 400 dessas RTVs. Entre as principais redes privilegiadas estavam as ligadas a igrejas; já no grupo de prefeituras, destacavam-se as comandadas por partidos da base aliada ao governo federal, a exemplo de 35 ocupadas pelo PMDB em Goiás e outras 28 comandadas pelo PPB no Rio Grande do Sul. 
A operação de retransmissoras de TV diretamente por prefeituras foi tema de outra pesquisa, uma década depois, realizada por Görgen (2007). No interior do país, onde as grandes redes hesitam em operar diretamente por desinteresse econômico, políticos comprometeram-se, como plataforma eleitoral, a levar os sinais das principais emissoras aos munícipes. O resultado dessa predileção foi a obtenção das outorgas diretamente pelas prefeituras, situação invisível aos olhos de grande parte da sociedade, mas que chegou a responder por quase um terço de todas as RTVs instaladas no país:

No que tange às RTVs, parece haver dois tipos de apropriação do público pelo privado. Uma direta, a partir da exploração da estrutura de uma estação controlada por uma municipalidade, como se a rede privada dela tivesse posse. A outra apropriação patrimonial do sistema se dá de forma mais difusa. Reside no fato de que a presença da rede em determinado local lhe gera rendimentos particulares na comercialização dos espaços publicitários fixados de acordo com o alcance de sua cobertura e de sua audiência, nada sendo repassado à Prefeitura [...] (Görgen, 2007, p. 13-14).

Em 2012, o Ministério das Comunicações celebrou um acordo de cooperação técnica com a Anatel. O objetivo: garantir o acesso da população à programação da TV aberta. O efeito concreto: impedir que os fiscais da Agência lacrem estações clandestinas até o fim dos processos de outorga, caso haja menos de três estações licenciadas no município.

Ressalte-se, brevemente, que as polêmicas sobre outorgas de novas estações não se restringiram ao mundo das retransmissoras. Nesse sentido, vale citar, por exemplo, pesquisa de Motter (1994), que investigou a distribuição de concessões e permissões (os instrumentos usados à época) durante a Assembleia Nacional Constituinte. Foram distribuídas, então, 1.028 outorgas, equivalentes a cerca de um terço dentre as feitas no Brasil até o início do governo Collor. O ritmo aumentou no fim de 1988 e 91 deputados constituintes foram contemplados, dos quais mais de $90 \%$ votaram a favor do presidencialismo como sistema de governo e em um mandato de cinco anos para o então Presidente da República, José Sarney.

As possibilidades de uso político do processo de outorga foram restringidas nas décadas seguintes. No governo de Fernando Henrique Cardoso foi firmado o entendimento sobre a necessidade de processo licitatório para a outorga de emissoras comerciais de rádio e TV; já no Governo Dilma Rousseff, foram regulamentados processos seletivos para serviços antes objeto de discricionariedade, como o de RTVs primárias (que têm direito à proteção contra interferência) e o de radiodifusão educativa; e foram aprimorados ritos de outros 
serviços, como o de radiodifusão comunitária (Pieranti, 2017). Autorizações de RTVs secundárias (que não contam com proteção contra interferência de outras estações), no entanto, continuaram a ser discricionárias.

\section{Distribuição geográfica das estações locais de TV}

Do total de 5.570 municípios brasileiros, apenas 802 (14,40\%) contam com uma estação local de TV. A distribuição é consideravelmente desigual, se observada a situação em cada macrorregião geográfica do país:

Tabela 2: Municípios com estação local de TV (por região)

\begin{tabular}{|c|c|c|c|}
\hline & $\begin{array}{l}\text { Municípios com } \\
\text { uma estação } \\
\text { (TV+RTV_AmL) }\end{array}$ & $\begin{array}{l}\text { Municípios } \\
\text { Brasil }\end{array}$ & $\%$ \\
\hline Brasil & 802 & 5570 & 14,40 \\
\hline Região N & 323 & 450 & 71,78 \\
\hline Região NE & 170 & 1794 & 9,48 \\
\hline Região CO & 124 & 467 & 26,55 \\
\hline Região SE & 126 & 1668 & 7,55 \\
\hline Região S & 59 & 1191 & 4,95 \\
\hline
\end{tabular}

Fonte: Elaborada pelo autor

Apesar do pequeno número de municípios com estações locais de TV pelo país, neles reside a maior parte da população (52,35\%):

Tabela 3: População residente em municípios com estação local de TV

\begin{tabular}{|l|r|r|r|}
\hline & $\begin{array}{l}|l| \\
\text { População dos mun.com }\end{array}$ & População total & \% \\
\hline Brasil & 108.676 .360 & 207.613 .394 & $\mathbf{5 2 , 3 5}$ \\
\hline Região N & 16.419 .746 & 17.928 .142 & $\mathbf{9 1 , 5 9}$ \\
\hline Região NE & 22.065 .273 & 57.214 .683 & $\mathbf{3 8 , 5 7}$ \\
\hline Região CO & 10.308 .450 & 15.875 .907 & $\mathbf{6 4 , 9 3}$ \\
\hline Região SE & 47.320 .467 & 86.949 .714 & $\mathbf{5 4 , 4 2}$ \\
\hline Região S & 12.562 .424 & 29.644 .948 & $\mathbf{4 2 , 3 8}$ \\
\hline
\end{tabular}

Fonte: Elaborada pelo autor 
Existem atualmente 42 municípios no país com população acima de 500 mil habitantes, dos quais sete $(16,6 \%)$ não contam com uma estação local de TV. Desses, dois estão no Rio de Janeiro, Duque de Caxias (com 890.997 habitantes) e Nova Iguaçu (798.647); dois em São Paulo, São Bernardo do Campo (827.437) e Santo André (715.231); um em Pernambuco, Jaboatão dos Guararapes (695.956); um em Goiás, Aparecida de Goiânia (542.090); e um no Espírito Santo, Serra (502.618).

Em 107 municípios brasileiros, a população é superior a 200 mil e inferior a 500 mil habitantes. Em 36 deles $(33,6 \%)$ também não existe estação local de TV:

Tabela 4: Municípios com população entre 200 e 500 mil habitantes sem estação local de TV

\begin{tabular}{|l|l|l|l|l|c|}
\hline UF & Município & População & UF & Município & População \\
\hline RJ & Belford Roxo & 495.783 & RS & Gravataí & 275.146 \\
\hline ES & Vila Velha & 486.388 & SP & Sumaré & 273.007 \\
\hline SP & Mauá & 462.005 & SP & Embu das Artes & 267.054 \\
\hline RJ & São João de Meriti & 460.461 & RN & Parnamirim & 254.709 \\
\hline SP & Diadema & 417.869 & RS & Viamão & 253.717 \\
\hline SP & Jundiaí & 409.497 & RJ & Macaé & 244.139 \\
\hline SP & Carapicuíba & 396.587 & SC & São José & 239.718 \\
\hline PE & Olinda & 390.771 & SP & Indaiatuba & 239.602 \\
\hline ES & Cariacica & 387.368 & RJ & Magé & 237.420 \\
\hline SP & Itaquaquecetuba & 360.657 & PR & Colombo & 237.402 \\
\hline RS & Canoas & 343.853 & RJ & Itaboraí & 232.394 \\
\hline MG & Ribeirão das Neves & 328.871 & RS & São Leopoldo & 230.914 \\
\hline PE & Paulista & 328.353 & SP & Jacareí & 229.851 \\
\hline SP & Praia Grande & 310.024 & SP & Itapevi & 229.502 \\
\hline SP & São José dos Pinhais & 307.530 & SP & Hortolândia & 222.186 \\
\hline BA & Camaçari & 296.893 & MG & Santa Luzia & 218.897 \\
\hline SP & Suzano & 290.769 & RS & Alvorada & 208.177 \\
\hline SP & Taboão da Serra & 279.634 & PE & Cabo de Santo & 204.653 \\
\hline
\end{tabular}

Fonte: Elaborada pelo autor

Uma rápida análise desses dois grupos de municípios permite identificar que vários deles estão próximos às capitais ou a outras grandes cidades que contam com estações locais de TV. Por sua importância regional, notícias sobre essas localidades frequentam os telejornais produzidos em estações localizadas nos municípios vizinhos. Esse é o caso, por exemplo, dos quatro municípios localizados na Baixada Fluminense, perto da capital do Rio de Janeiro: Duque de 
Caxias, Nova Iguaçu, Belford Roxo e São João do Meriti. Por mais que esse seja um atenuante, pode-se dizer que 16.024.777 cidadãos residem em 43 grandes municípios brasileiros, com população superior a 200 mil habitantes, que não contam com uma estação local de TV. Esse total equivale a $8 \%$ da população brasileira.

Uma comparação entre a situação da Amazônia Legal e a do restante do país leva ao seguinte resultado:

Tabela 5: Municípios com estação local de TV (Amazônia Legal e outros)

\begin{tabular}{|l|r|r|r|r|l|l|}
\hline & $\begin{array}{l}\text { Mun. com } \\
\text { estação local }\end{array}$ & $\begin{array}{l}\text { Total de } \\
\text { municípios }\end{array}$ & \% & $\begin{array}{l}\text { Pop. Mun. com } \\
\text { uma estação }\end{array}$ & $\begin{array}{l}\text { População } \\
\text { total }\end{array}$ & $\%$ \\
\hline $\begin{array}{l}\text { Amazônia } \\
\text { Legal }\end{array}$ & 565 & 772 & $\mathbf{7 3 , 1 9}$ & 24.739 .425 & 27.091 .198 & $\mathbf{9 1 , 3 2}$ \\
\hline Outros & 237 & 4798 & $\mathbf{4 , 9 4}$ & 83.936 .935 & 180.522 .196 & $\mathbf{4 6 , 5 0}$ \\
\hline
\end{tabular}

Fonte: Elaborada pelo autor

A constatação mais evidente é o quase total atendimento da população residente na Amazônia Legal por estações locais de TV. Ainda que estejam em 73,19\% dos municípios da região, neles residem mais de $91 \%$ da população.

Já o número de municípios com uma geradora de TV, fora da Amazônia Legal, chama atenção em sentido oposto. Passados mais de 67 anos da instalação da primeira emissora no país, apenas 237 municípios do país (4,25\% do total ou 4,94\% de todo o grupo, excluídos os da Amazônia Legal) contam com uma emissora de TV. A população residente nesses municípios aproximase da metade do potencial total. Se, na Amazônia Legal, o cenário poderia ser chamado de quase universalização, fora dela a TV local ainda está distante da maior parte da população.

Cenário semelhante pode ser observado nos estados. Apenas no Distrito Federal, no Acre e em Roraima todos os municípios contam com, pelo menos, uma estação local de TV. A explicação para o primeiro caso é fácil afinal, no caso do DF, contabiliza-se apenas Brasília. Nos demais, observa-se a capilaridade do meio TV, com um cenário semelhante ao de outros estados da Amazônia Legal. Vale citar o exemplo do Acre, no qual existem apenas sete geradoras em dois municípios (a capital Rio Branco e Mâncio Lima); os demais 
são cobertos por 96 RTVs que podem inserir programação localmente, nos limites previstos na legislação. A TV Aldeia, emissora educativa vinculada ao governo estadual, depois de atravessar período em que chegou a interromper suas atividades na década de 1990, dispõe diretamente de outorgas próprias em 21 dos 22 municípios (não tem outorga apenas em Tarauacá, com cerca de 40 mil habitantes). A tabela abaixo apresenta os estados com maior cobertura de estações locais de TV:

Tabela 6: UFs com maior presença de estações locais de TV

\begin{tabular}{|c|c|c|c|c|c|c|}
\hline & $\begin{array}{c}\text { Mun. com uma } \\
\text { estação }\end{array}$ & Mun. UF & $\%$ & $\begin{array}{l}\text { Mun. com uma } \\
\text { estação (pop.) }\end{array}$ & Pop. total & $\%$ \\
\hline$A C$ & 22 & 22 & 100 & 829.619 & 829.619 & 100 \\
\hline DF & 1 & 1 & 100 & 3.039 .444 & 3.039 .444 & 100 \\
\hline RR & 15 & 15 & 100 & 522.636 & 522.636 & 100 \\
\hline AM & 61 & 62 & 98,39 & 4.034 .424 & 4.063 .614 & 99,28 \\
\hline$A P$ & 15 & 16 & 93,75 & 777.335 & 797.722 & 97,44 \\
\hline MT & 108 & 141 & 76,60 & 3.129 .867 & 3.344 .544 & 93,58 \\
\hline MA & 134 & 181 & 74,03 & 5.189 .812 & 5.818 .512 & 89,19 \\
\hline PA & 103 & 144 & 71,53 & 7.338.915 & 8.358 .569 & 87,80 \\
\hline RO & 32 & 52 & 61,54 & 1.616 .016 & 1.805 .788 & 89,49 \\
\hline TO & 75 & 139 & 53,96 & 1.300 .801 & 1.550 .194 & 83,91 \\
\hline RJ & 10 & 92 & 10,87 & 983.0629 & 16.718 .956 & 58,80 \\
\hline
\end{tabular}

Fonte: Elaborada pelo autor

À exceção do DF, todos os 10 primeiros colocados integram a Amazônia Legal (os números apresentados na tabela anterior para o Maranhão refletem apenas os municípios integrantes da Amazônia Legal). A 11a UF é o Rio de Janeiro, porém bem distante do cenário observado na Amazônia Legal: com diferença percentual, em relação ao Tocantins, o estado anterior na classificação, de mais de $43 \%$ e de $25 \%$, respectivamente, em relação ao total de municípios e de população. As duas tabelas seguintes apontam os piores colocados, se considerados, de forma independente, os critérios de percentual de municípios e de população:

Tabela 7: UFs com menor presença de estações locais de TV (critério: 
municípios)

\begin{tabular}{|l|r|r|r|r|r|r|}
\hline & $\begin{array}{c}\text { Mun. com uma } \\
\text { estação }\end{array}$ & Mun. UF & \multicolumn{1}{c|}{$\%$} & \multicolumn{1}{c|}{$\begin{array}{c}\text { Mun. com uma } \\
\text { estação (pop.) }\end{array}$} & Pop. total & $\%$ \\
\hline BA & 8 & 417 & $\mathbf{1 , 9 2}$ & 4.841 .652 & 15.327 .633 & $\mathbf{3 1 , 5 9}$ \\
\hline RN & 3 & 167 & $\mathbf{1 , 8 0}$ & 1.196 .389 & 3.507 .003 & $\mathbf{3 4 , 1 1}$ \\
\hline PB & 2 & 223 & $\mathbf{0 , 9 0}$ & 1.221 .930 & 4.002 .896 & $\mathbf{3 0 , 5 3}$ \\
\hline
\end{tabular}

Fonte: Elaborada pelo autor

Tabela 8: UFs com menor presença de estações locais de TV (critério: população)

\begin{tabular}{|l|r|r|r|r|r|r|}
\hline & \multicolumn{1}{|c|}{$\begin{array}{c}\text { Mun. com } \\
\text { uma estação }\end{array}$} & Mun. UF & \multicolumn{1}{c|}{$\%$} & $\begin{array}{c}\text { Mun. com uma } \\
\text { estação (pop.) }\end{array}$ & Pop. total & $\%$ \\
\hline SE & 2 & 75 & $\mathbf{2 , 6 7}$ & 679.913 & 2.288 .116 & $\mathbf{2 9 , 7 1}$ \\
\hline ES & 6 & 78 & $\mathbf{7 , 6 9}$ & 1.119 .977 & 4.016 .356 & $\mathbf{2 7 , 8 9}$ \\
\hline PE & 5 & 185 & $\mathbf{2 , 7 0}$ & 2.473 .598 & 9.473 .266 & $\mathbf{2 6 , 1 1}$ \\
\hline
\end{tabular}

Fonte: Elaborada pelo autor

Dos nove estados que integram a Amazônia Legal, apenas o Maranhão é formado também por municípios localizados fora desta região. Assim, para efeito de exemplo, faz-se interessante comparar as duas realidades em um mesmo estado:

Tabela 9: Municípios com estação local de TV no Maranhão

\begin{tabular}{|l|r|r|r|r|r|r|}
\hline & \multicolumn{1}{|c|}{$\begin{array}{c}\text { Mun. com } \\
\text { uma estação }\end{array}$} & $\begin{array}{c}\text { Mun. } \\
\text { UF }\end{array}$ & \multicolumn{1}{c|}{$\%$} & $\begin{array}{l}\text { Mun. com uma } \\
\text { estação (pop.) }\end{array}$ & Pop. total & $\%$ \\
\hline MA-AL & 134 & 181 & $\mathbf{7 4 , 0 3}$ & 5.189 .812 & 5.818 .512 & $\mathbf{8 9 , 1 9}$ \\
\hline MA $^{*}$ & 2 & 36 & $\mathbf{5 , 5 6}$ & 192.953 & 1.181 .717 & $\mathbf{1 6 , 3 3}$ \\
\hline MA & 136 & 217 & $\mathbf{6 2 , 6 7}$ & 5.382 .765 & 7.000 .229 & $\mathbf{7 6 , 8 9}$ \\
\hline
\end{tabular}

Fonte: Elaborada pelo autor

Da primeira linha da tabela anterior constam os municípios maranhenses que integram a Amazônia Legal, com percentuais compatíveis com os 
observados em outros estados desta mesma região. Na segunda, marcada com um asterisco, figuram os municípios maranhenses localizados a leste do meridiano de $44^{\circ}$ e, portanto, fora da Amazônia Legal. Nesse caso, observamse percentuais similares aos dos piores resultados das tabelas anteriores - na verdade, se esses municípios compusessem um estado, sua realidade seria a pior do país, se considerado o critério populacional. A terceira linha reflete o estado como um todo, observando-se, ainda, um resultado compatível com o observado em outros estados da Amazônia Legal.

\section{Considerações Finais}

Como tantos outros aspectos da realidade brasileira, existe considerável desigualdade regional quando se verifica a distribuição de estações locais de TV no país. Neste caso concreto, no entanto, diferentemente de tantos outros, o cenário pende positivamente para a região Norte do país e para os demais estados que compõem a Amazônia Legal. Nessa região, conforme apresentado, $73,19 \%$ dos municípios, onde residem $91,32 \%$ da população, contam com ao menos uma estação local de TV; no restante do país, esses percentuais caem respectivamente para 4,94\% e 46,50\%. Assim, pode-se dizer que a interiorização da TV, com sinais locais, já em prática há mais de 30 anos, é uma política pública de sucesso considerável na Amazônia Legal.

A despeito dessa constatação, é preciso, também, ressaltar problemas dessa política. Ao menos dois deles saltam aos olhos. O primeiro: a maior parte das estações locais de TV no Brasil é de pequeno porte, sendo-lhes legalmente permitido inserir uma pequena parcela de conteúdos locais em sua programação. Em outras palavras, a interiorização de sinais locais de TV é um passo, porém tem efeitos limitados no que se refere à ampliação do direito à informação e ao estímulo do mercado local.

O segundo problema dialoga com o próprio cenário da mídia no Brasil. A proliferação de estações locais de TV na Amazônia Legal não é necessariamente sinônimo de mais pluralismo. Este artigo não se dedicou a examinar as redes atuantes na Amazônia Legal, mas, de forma geral, também nessa região predomina a retransmissão da programação-base das grandes redes nacionais privadas, com inserções locais. Os instrumentos normativos que criaram regras excepcionais para as RTVs ali atuantes não previram mecanismos diferenciados para garantir a efetivação de outros comandos constitucionais, tais como a complementariedade dos sistemas privado, público e estatal de radiodifusão e o estímulo à transmissão de conteúdos de produção independente. Tampouco foram estabelecidas contrapartidas, a serem oferecidas pelas empresas, para a liberalidade de que dispõem (no caso, uma estação local de TV, mediante 
outorga simplificada e gratuita, com possibilidade de inserção de conteúdos locais).

Exceção feita ao cenário da Amazônia Legal, ainda assim quando analisada isoladamente, a TV não se configura como meio local de comunicação. Os números apresentados levam a essa conclusão de forma clara - afinal, em apenas $14,4 \%$ dos municípios brasileiros, onde residem $52,35 \%$ da população, funciona, pelo menos, uma estação local de TV. O cenário é mais grave na região Nordeste, onde apenas $38,57 \%$ da população podem assistir a uma programação gerada, ainda que em parte, no próprio município onde residem.

Ao se analisar os números apresentados, deve-se ter cuidado com possíveis falsas conclusões, que, em alguns casos, contrariariam o senso comum. Por exemplo: pode-se dizer que a população da Amazônia Legal é mais bem "informada", já que reside, em grande parte, em municípios cobertos por estações locais de TV? Certamente não se pode cometer esta generalização, já que o grau de informação disponível está, em alguma medida, relacionado à variedade de redes e meios de comunicação em uma dada localidade. $E$, na Amazônia Legal, o acesso à internet, por exemplo, é bem mais precário que no resto do país.

Por fim, este estudo leva naturalmente a uma pergunta: considerando os percentuais verificados na Amazônia Legal, o benefício concedido às RTVs nesta região não deveria ser estendido aos demais municípios brasileiros? Assim, em tese, a sociedade como um todo tenderia a dispor de um maior volume de conteúdos locais, seriam gerados novos empregos, e o mercado local seria estimulado. O estudo aqui apresentado não permite traduzir em números esses benefícios (ou, pelo menos, estimá-los), o que seria necessário para propor a mudança da política pública. Pode-se, por outro lado, apenas registrar que essa mudança possivelmente enfrentaria a oposição de parte do setor da radiodifusão, sedimentado em um modelo de negócios centralizado, ainda que normalmente explicado como "federativo", que resguarda as janelas de maior audiência à programação nacional e olha enviesado para a possibilidade de proliferação de conteúdos locais. Ainda assim, os números observados em relação à Amazônia Legal sugerem que, pelo menos, essa hipótese deve ser levada em consideração na discussão de políticas públicas de radiodifusão.

\section{REFERÊNCIAS}

Anatel. Sistema Mosaico. Disponível em: < http://sistemas.anatel.gov.br/se/public/ view/b/srd.php>. Acesso em: 6 nov. 2017.

BRASIL. Lei n 5.173, de 27 de outubro de 1966. Diário Oficial da União, 31 out. 1966. 
Lei $n^{\circ}$ 12.527, de 18 de novembro de 2011. Diário Oficial da União, 18 nov. 2011.

CASTRO, Daniel. Consumo de TV explode, e Globo e Record têm melhor ano desde 2011. Notícias da TV, 5 set. 2017. Disponível em: <http://noticiasdatv.uol.com. $\mathrm{br} /$ noticia/televisao/consumo-de-tv-explode-e-globo-e-record-tem-melhorano-desde-2011--16660>. Acesso em: 14 dez. 2017.

COSTA, Sylvio; BRENER, Jayme. Coronelismo eletrônico: o governo Fernando Henrique e o novo capítulo de uma velha história. Comunicação \& Política, Rio de Janeiro, v. 4, n. 2, p. 29-53, 1997.

COUTINHO, Iluska; MATA, Jhonatan. Uma programação para chamar de sua: televisão, narrativa e participação popular. Contemporânea, v. 8, n. 2, p. 1-19, dez. 2010. Disponível em: <https://portalseer.ufba.br/index.php/contemporaneaposcom/ article/viewFile/4788/3568>. Acesso em: 18 dez. 2017.

EBU. Audience Trends Television 2016. EBU, 2016.

Audience Trends Television 2017 - Public version. EBU, 2017. Disponível em: <https://www.ebu.ch/publications>. Acesso em: 20 ago. 2017.

FELTRIN, Ricardo. Consumo mostra que TV aberta está longe de morrer, diz diretora da Kantar. UOL, 24 ago. 2017. Disponível em: <https://tvefamosos.uol.com.br/ noticias/ooops/2017/08/24/consumo-mostra-que-tv-aberta-esta-longe-demorrer-diz-diretora-da-kantar.htm>.Acesso em: 14 dez. 2017.

GÖRGEN, James. Redes de televisão e prefeituras: uma dominação consentida. In: COMPOLÍTICA - CONGRESSO DA ASSOCIAÇÃO BRASILEIRA DE PESQUISADORES DE COMUNICAÇÃO E POLÍTICA, II, 2007, Belo Horizonte. Anais... Belo Horizonte: Compolítica, 2007. 1 CD-ROM.

IBGE. Estimativas de população para 31 de outubro de 2017. Disponível em: <https://ww2.ibge.gov.br/home/estatistica/populacao/estimativa2017/ estimativa_tcu.shtm>. Acesso em: 6 nov. 2017.

LOBATO, Elvira. Antenas da Floresta: a saga das TVs da Amazônia. Rio de Janeiro: Objetiva, 2017.

LOUREIRO, Luís Miguel. TV do ego: notícia de uma morte adiada? In: 60 SOPCOM, 2009, Portugal. Anais... Disponível em: <https://www.researchgate.net/ publication/277247903_TV_do_ego_noticia_de_uma_morte_adiada $>$. Acesso em: 15 dez. 2017.

MOTTER, Paulino. O uso político das concessões das emissoras de rádio e televisão no governo Sarney. Comunicação \& Política, Rio de Janeiro, vol. 1, n. 1, p. 89-116, 1994. 
PIERANTI, Octavio Penna. Políticas Públicas de Radiodifusão no Governo Dilma. Brasília-DF: FAC Livros/UnB, 2017. Disponível em: <https://faclivros.files. wordpress.com/2017/09/faclivros_politicasradiodifusaogovdilma.pdf $>$. Acesso em: 20 out. 2017.

PODER360. Mais da metade dos brasileiros usam a TV como principal fonte de informação. Poder 360, 19 set. 2017. Disponível em: <https://www.poder360. com.br/midia/mais-da-metade-dos-brasileiros-usam-a-tv-com-principalfonte-de-informacao/>. Acesso em: 14 dez. 2017.

SECOM. Pesquisa Brasileira de Mídia 2016. 2016. Disponível em: <http://www. pesquisademidia.gov.br/>. Acesso em: 1 maio 2017.

\section{Dados do autor:}

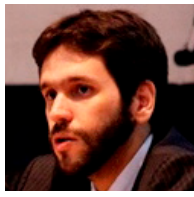

Octavio Penna Pieranti | octavio.pieranti@gmail.com

Laboratório de Estudos em Comunicação, Tecnologia e Educação Cidadã (Lecotec-Unesp) Doutor em Administração e Mestre em Administração Pública (EBAPE/FGV), com Pós-Doutorado em Comunicação (FAC-UnB). Pesquisador Emérito do Núcleo de Estudos em Administração Brasileira (AbrasUFF) e Pesquisador do Laboratório de Estudos em Comunicação, Tecnologia e Educação Cidadã (LecotecUnesp)

Endereço do autor:

Laboratório de Estudos em Comunicação, Tecnologia e Educação Cidadã da Universidade Estadual Paulista Júlio de Mesquita Filho (Lecotec-Unesp)

Av. Eng. Luiz Edmundo Carrijo Coube, 14-01

Bairro Vargem Limpa

17.033-360 - Bauru/SP 